\title{
EHMTI-0160. New questionnaire - impact of migraine, tension-type headache and neck pain: a validation study
}

\author{
LS Krøll ${ }^{*}$, C Sjödahl Hammarlund ${ }^{2}$, G Gard $^{2}, \mathrm{RH}$ Jensen $^{1}$ \\ From 4th European Headache and Migraine Trust International Congress: EHMTIC 2014 \\ Copenhagen, Denmark. 18-21 September 2014
}

\section{Introduction}

Migraine often include co-existing tension-type headache (TTH) and neck pain (NP). Currently no questionnaires cover these co-morbidities. A new questionnaire "Impact of Migraine, Tension-Type Headache and Neck Pain" (Impact M-TTH-NP) was therefore needed.

Aim

To determine face and content validity of the newly developed Impact M-TTH-NP.

\section{Methods}

Nine migraine patients with co-existing TTH and NP participated in group interviews. Content validity was assessed by 13 headache experts. The Content Validity Index (CVI) at item (I-CVI) and at scale level (S-CVI/ Ave) was used together with the Average Deviation $(\mathrm{AD})$ index to assess interrater agreement.

\section{Results}

Impact M-TTH-NP showed acceptable face validity. Of 78 items twelve were revised and one was added based on group interviews and experts review. Seventy two items (92\%) obtained I-CVI $\geq 0.78$ (range 0.78-1.00) indicating excellent content validity, 71 items (91\%) obtained acceptable AD index. Nine items did not meet either the limit for excellent I-CVI and/or acceptable AD index. The overall S-CVI/Ave was 0.92 indicating an excellent content validity.

'Department of Neurology, Danish Headache Center, Copenhagen, Denmark Full list of author information is available at the end of the article

\section{Conclusions}

The Impact M-TTH-NP questionnaire showed acceptable face validity and excellent content validity and can be recommended for clinical studies of patients with migraine and co-existing TTH and NP.

No conflict of interest.

\section{Authors' details}

'Department of Neurology, Danish Headache Center, Copenhagen, Denmark. ${ }^{2}$ Department of Health Sciences, Lund University, Lund, Sweden.

Published: 18 September 2014

doi:10.1186/1129-2377-15-S1-D58

Cite this article as: Krøll et al: EHMTI-0160. New questionnaire - impact of migraine, tension-type headache and neck pain: a validation study. The Journal of Headache and Pain 2014 15(Suppl 1):D58.

\section{SpringerOpen ${ }^{\odot}$}

( 2014 Krøll et al; licensee Springer. This is an Open Access article distributed under the terms of the Creative Commons Attribution License (http://creativecommons.org/licenses/by/2.0), which permits unrestricted use, distribution, and reproduction in any medium, provided the original work is properly cited.
Submit your manuscript to a SpringerOpen ${ }^{\circ}$ journal and benefit from:

- Convenient online submission

- Rigorous peer review

- Immediate publication on acceptance

- Open access: articles freely available online

- High visibility within the field

- Retaining the copyright to your article

Submit your next manuscript at $>$ springeropen.com 